\title{
The Application of MOOC in Teacher's Continuing Education
}

\author{
Xiaoxia Lu \\ School of Foreign Studies, Xi'an University, Xi'an, China \\ 1260728600@qq.com
}

\begin{abstract}
Keywords: Application; MOOC; Teacher's continuing education
\end{abstract}
\begin{abstract}
The emerge of MOOC, a new form of e-learning application platform, has quietly changed the mode of continuing education for teachers. The government's encouragement of using MOOC with positive policies and the social demand for teacher's continuing education are good opportunities for the application of MOOC in teacher's continuing education. Besides, using MOOC has advantages such as providing a variety of quality educational resources around the world for the learners, meeting the diverse needs of teacher learners, providing a fragmented learning approach for teacher learners, the student-centered curriculum organization and so on. When applying MOOC in teacher's continuing education, teacher trainers should design the MOOC courses carefully, starting from the course production, design of MOOC structure to MOOC video design. When applying MOOC in flipping classroom in teacher's continuing education, teacher trainers should focus on the application of MOOC in pre-class knowledge dissemination, the application of MOOC in classroom knowledge internalization and the application in after-class reflection. So, the application of MOOC in teacher continuing education not only enables teacher learners to achieve fragmented learning anytime and anywhere, but also meets the individual needs of teacher learners.
\end{abstract}

\section{Introduction}

With the application and popularization of computer and information networks and the advancement of multimedia technology, the application of modern information technology to carry out continuing education via distance education has become the trend of modern teachers' continuing education. It realizes the transformation of the continuing education mode to diversity and flexibility with the characteristics of high utilization of educational resources and optimization of educational benefits.

The "Thirteenth Five-Year Plan for National Economic and Social Development of the People's Republic of China" issued by the State Council clearly stated: "Promote various learning resources to be opened and shared, run open universities, develop online education and distance education and integrate various digital education resources to provide services to the whole society. Establish a personal learning account and credit accumulative system, unimpeded continuing education and lifelong learning channels, develop a national qualifications framework, promote non-academic education learning outcomes and mutual recognition of vocational skills and grade credit conversion. [1]" According to the strategic goal set by the 13th Five-Year Plan, the teacher's continuing education model should develop in the direction of"Internet + education" in the next five years, and continue to innovate in order to keep up with the rapid development of the information age and build a learning society and realize the ultimate goal of achieving lifelong education. The "Internet + Education" model is the inevitable development of the information age, and it also brings opportunities and challenges for the reform of teachers' continuing education model.

The emerge of MOOC, a new form of e-learning application platform, has quietly changed the mode of continuing education for teachers. The use of MOOC in teacher continuing education has become a necessity for the development. "MOOC is a learning revolution, and its influence is by no means limited to universities. It will be of positive significance to promote the development of continuing education, create a flexible and open lifelong education system, and build a learning society that everyone can learn at any place and at any time. [2]"

\section{Problems in Present Teacher's Continuing Education in China}

The contradiction between teaching and study

The contradiction between work and study is a prominent problem for teachers to engage in continuing education, especially for rural teachers. Lu Bo (2007) pointed out that heavy teaching task is an important obstacle for to teachers to participate in continuing education. In some backward and poor places, the number of teachers in the school is insufficient, and the workload of each teacher is very large. Teachers just can complete the teaching work in the school, but it is very difficult for them to find time to get out for the continuing education. If they want to improve themselves, they can only study during the summer vacation or other time. Lian Yifeng (2010) and Guo Ling (2007) also pointed out that the workload of primary and secondary school teachers is large, and it's difficult to guarantee them to have the time for continuing education[4][5]. 


\section{Not very relevant and practical content of teacher's continuing education}

At present, some teaching content of continuing education for primary and secondary school teachers lack relevance and practicality.

First, the curriculum is set to "one size fits all", which is not designed for different levels of teachers in different districts and areas. The teaching content of continuing education for teachers in rural area is still the one for urban teachers, which led to no desired effect for rural teachers. Shi Yuxin (2008) pointed in his paper that there was about $60 \%$ teachers believed that the training organization used the same teaching materials for all teachers in the training, neglecting the different level and the teaching of the teachers participating in the training. As a result, the training is neither targeted nor practical[6].

Second, the content of teaching is over-theorized and monotonous. Li Ping (2008) and Zhu Xiaodong (2008) believe that the content for teacher's continuing education, on the one hand, is too theoretical, and there is not much guidance for the practical teaching; on the other hand, teachers giving lessons of continuing education neglect the different needs of the trained teachers when selecting the content of the training, and thus the enthusiasm of the teachers participating in continuing education cannot be stimulated, which is a waste of teaching resources[7][8].

\section{Single mode of teacher's continuing education}

The single mode of the teacher's continuing education is an important factor influencing the effectiveness of the training, which cannot meet the needs of the majority of primary and secondary school teachers to continue their education. More and more researchers are arguing that the models for teacher's continuing education should be diverse. Huang Yu and Cao Wangjin (2002) believe that it is not enough to rely on the traditional face-to-face teaching and classroom guidance[9]. In the continuing education for primary and secondary school teachers, it is flexible and diverse to use modern educational technology, audio-visual means, multimedia and networks to carry out individualized teaching, which can solve not only the contradiction between work and learning, but also the problems of time and region.

\section{Teachers' continuing education lacking systematicity}

The continuing education of teacher is a systematic work, which is coherent and unified. It should be considered from the development of teachers' education throughout their careers. Therefore, an institutionalized and normative cooperative relationship should be established between the education management department, the continuing education institution, the school, the teacher group and the individual. If the relationship between them is unstable, too casual, and if the interests are always put first, the continuing education of teachers is prone to various problems such as lack of theme, subject emptying and poor content targeting.

\section{Understanding MOOC}

Massive Open Online Course (MOOC) is a curriculum model that combines the learning management system with more open network resources based on network technology and intelligent technology[10]. Taking advantage of network, communication, multimedia technology and modern teaching methods, MOOC provides a large number of high-quality educational resources to learners. It has become a hot spot of education informatization and attracts the attention of domestic and foreign education fields. Many MOOC courses attract many learners to participate in the study once they are launched because they are gradually become bridges between lecturers and learners, and they are not limited by time and space[11].

Therefore, MOOC can be said to be a great innovation in the history of education. Compared with remote network teaching, MOOC has its own unique characteristics, which are embodied in the following points:

First, the coverage and scale of the MOOC is large. Because MOOC is mainly developed based on the network platform, it is different from the traditional classroom teaching. It can accept various forms of learning participation, there is no limit on the number of participants, and the learning schedule is very flexible, thus attracting globally.

Second, MOOC has a strong openness, breaking through the limitations of the tangible teaching "wall" in traditional education. As long as learners have online learning conditions and have a willingness to learn, they can learn through the MOOC platform. In other words, MOOC provides a fair learning platform for learners of different ages, identities, geographies and occupations. Thus it makes low-threshold, borderless lifelong learning possible.

Third, MOOC is free charge. Anyone studying through the MOOC platform can enjoy the online courses with no charge, no tuition fees, and no entrance exams.

In addition, teacher learners can register and learn at any time and any place through the MOOC platform, which is not only limited by time and space, but also can realize fragmented segmentation learning according to their own interests. 


\section{Adult Learning Theory}

In 1968, Professor Malcolm Knowles of School of Education of Boston University put forward the concept of "adult education" to distinguish traditional youth-oriented schools Education. Knowles believes that adult students have the following six basic characteristics:

1.Need to know: Adults need to know the reason for learning something.

2.Foundation: Experience (including error) provides the basis for learning activities.

3.Self-concept: Adults need to be responsible for their decisions on education; involvement in the planning and evaluation of their instruction.

4.Readiness: Adults are most interested in learning subjects having immediate relevance to their work and/or personal lives.

5.Orientation: Adult learning is problem-centered rather than content-oriented.

6.Motivation: Adults respond better to internal versus external motivators[12].

According to Knowles theory of adult learning, adult individuals have been mature physically and psychologically. Their self-concepts have been transformed from dependent personality to independent personality. They have strong learning autonomy and their demand for continuing learning is also diverse, multi-level, social, and other characteristics $[13]$.

Adult learning theory has great enlightenment for teachers' continuing education and training. First of all, teacher learner's learning has strong need for practicability. One of the main motives for teachers to participate in continuing education is to solve their problems and confusion in their teaching practice. So it is difficult to attract the teacher learners if the knowledge and skills providing for them cannot be connected in practice, and thus their initiative of learning can not be exerted. The training that can solve the real problems will stimulate the interest of the trainees.

The motivation for adult learning is not only due to the arousal of internal drive, but also to external stimuli. Therefore, the "practical" motivation of adult learning in teachers' continuing education must be recognized and the specific needs behind the motivation must be understood.

What's more, the personal experience of teachers and the subjective status of teachers should be respected in the training. As adult learners, teachers have accumulated certain teaching experience before the training. Therefore, trainers should take into full consideration of the influence of the trainee's past experience on the learning, and have a good knowledge that teacher learners have strong autonomy and independence and that they know what knowledge they need and what gap they have to a certain extent. When designing the training course, trainers should not only consider the requirements of the current task for the teacher, but also pay attention to the gap between the current situation of the teachers, the target performance, and the subjective needs of individual teachers in the training.

\section{The opportunities and advantages of using MOOC in teacher continuing education}

Teacher learners have accumulated some experience in daily life, work and study. They have relatively mature personality, their value orientation has been basically fixed, and they have a clearer learning objectives than students. Therefore, compared with the average students, teacher learners have their own learning characteristics, such as the intrinsic learning motivation, rich learning experience and the initiative of learning[14]. It is because teacher learners in continuing education have these characteristics of learning that the application of MOOC in teacher continuing education has greater advantages and opportunities. .

\section{Opportunities of using MOOC}

Chinese government encourages the application of MOOC in continuing education for teachers and support this with positive policy. Therefore, it is necessary to attach great importance to the informationization of education. For the continuing education of teachers, the innovation of education concept is its forerunner of informationization, and the core is the innovation of education mode and learning style. China's development plan on informatization indicates that the informatization of teachers' continuing education should be based on the construction of information-based learning environment, and an education platform where everyone can enjoy high-quality curriculum resources, and MOOC is the very education platform supported by the state[15].

In addition, the construction of this network sharing education platform can effectively solve the problem of uneven distribution of educational resources in China, and can greatly improve the quality of education in China.

The society has great demand for teachers' continuing education. The 21 st century is an era of knowledge economy and an era of talent competition. More and more teachers are eager to continue learning and improve their teaching technique so as to keep up with the rapid developing society, and continuing education for teachers is an important way to realize the aim. It can be seen that the social needs of teachers for continuing education are very strong. However, the traditional form of continuing education is difficult to meet the learning needs of teachers of different level, especially the primary and secondary school teachers in rural areas. The emergence of MOOC, with its high-quality teaching resources and its flexible way of learning, meets the learning needs of the 
teachers.

\section{The Advantages of Using MOOC}

1. The quality courses offered by MOOC allow adult learners to learn the most authoritative knowledge in the world. MOOC brings together a variety of quality educational resources around the world. At present, China has XuetangX, Chinese University MOOC, Tsinghua Alliance, Uniform Education, Good University Online and other 8 comprehensive MOOC learning platforms. Moreover, they have cooperated with different universities, including the quality courses not only of well-known universities in China, but also of well-known foreign universities such as Harvard, Cambridge, and Stanford University. MOOC has the curriculum resources provided by the world's best teaching groups, and adult learners can learn world-class and most authoritative knowledge and skills through the MOOC platform [16]. In addition, the micro-courses can only be uploaded to the MOOC platform after careful selection and eligibility, which guarantees the quality of the courses.

2.MOOC's extensive curriculum content meets the diverse needs of teacher learners to continue learning.

MOOC content covers a wide range of topics, such as economics, management, mathematics, statistics, engineering, computers and humanities and social sciences. In the continuing education of teachers, learners generally have relatively clear learning goals, and they even know more about what they need to learn than their teacher trainers. Therefore, with MOOC, teachers continuing their learning could choose the course they want to learn according to their own interests or their own needs. But in traditional teaching, what should be taught is decided by the teacher trainer alone or the teacher trainee learn what the teacher trainer teaches. So the application of MOOC in continuing education for teachers will be more in line with the needs of adult learners.

3. MOO's online openness provides a fragmented learning approach for continuing education for teachers. In traditional continuing education for teachers, learners must participate in fixed face to face classroom teaching. Most teacher learners have heavy load of teaching in their schools, and they do not have much time to participate in classroom teaching. So, the application of MOOC in teacher continuing education breaks the limitations of the learning time and space, and teacher learners can make use of their free time to achieve fragmented learning. Besides, MOOC's information sources and evaluation processes are open, and the network is the primary medium for MOOC to gather and disseminate knowledge. Therefore, as long as learners have computers and networks, they can learn the courses offered by MOOC anytime, anywhere via the Internet.

4. The curriculum organization of MOOC is student-centered, which is in line with the characteristics of adult learning. The course structure is based on the characteristics of knowledge blocks, using dynamic, fragmented, relatively independent small video to display each knowledge point. Topics will also be interspersed with quizzes, assignments, discussions, etc. to help learners consolidate what they have learned and get feedback timely. Learners can also interact with teachers and classmates through learning communities, social media, etc., and can also send relevant learning materials while asking questions and answering questions. Thus teaching resources can be dynamically updated, and then the teaching and learning are truly achieved. Organizing in this way, MOOC courses focus on guidance and communication, and is conducive to stimulating learners' interest in acquiring knowledge. MOOC's "building block" course organization is very suitable for teachers participating continuing education. They can use the fragmented time of work to learn, and specifically skip or repeat some knowledge points according to their own needs. It is easier for them to control their own learning progress. At the same time, the construction of the learning network can help them find a sense of belonging, making peer-to-peer cooperative learning and group cooperative learning possible.

5. The application of MOOC is conducive to teachers' continuing education. Web-based and not limited by time and space, MOOC can provide excellent curriculum resources for the majority of frontline teachers, and create a platform and the environment for teachers and teachers, teachers and professionals to communicate and discuss. It can play the subjectivity of teachers' teaching and research activities, and makes up for the shortcomings of the traditional teaching and research model. MOOC's characteristics of "large scale", "openness" and "online", as well as high participation, strong constraints and multiple interactions, can better transform learners' desire to acquire knowledge into specific learning behaviors. At the same time, it also helps to promote the improvement of teachers' education concepts and teaching methods. On the basis of traditional school-based teaching and research, teachers need to make full use of the convenience of the Internet platform, combine the advantages of MOOC courses to improve their level of applied information technology, update their teaching ideas, improve their teaching models, their teaching effects, and then promote self-professional ability.

\section{The application of MOOC}

Construction of MOOC course in teacher continuing education

Course production of MOOC The MOOC course content is generally best with 15-20 minutes of video teaching time. According to the learning characteristics of adults, each video must be focused on the knowledge points in the layout and design so that teacher learners can make use of their free time to achieve fragmented and 
efficient learning. In order to test the learner's understanding and absorption of MOOC content, the corresponding content of the video teaching will be inserted with quiz, and there will be online tests after class. Through students' answers, this testing module can reflect learners' mastery of content well.

In short, in the continuing education of teachers, the design of the MOOC course should be short and succinct, with clear knowledge points, linking exercises with vivid explanations, and paying attention to the evaluation of learners' learning quality.

Structural design of MOOC The design of MOOC structure generally focuses on fragmenting knowledge points, which requires teacher trainers to learn to know what the teacher trainees need to learn, and then design and plan video teaching. The knowledge points should be explained according to scientific and logical sequence so that teacher learners can understand and absorb them in time.

MOOC video design The design of MOOC videos should emphasize the feature of shortness. Because teacher learners already have a certain learning experience, MOOC video content can be combined with interactive conversational teaching methods and animated and short film demonstrations to enhance the quality of teacher learners' knowledge absorption. For some more abstract knowledge points, pre-shooting and post-production can be used in MOOC video to achieve more realistic scene effects, which is easy for learners to understand. Each piece of MOOC video content should be designed to draw the learner's attention by its logic. For example, at the beginning of the video, question teaching method is used to attract teacher learners' attention and help them to think. Next, the knowledge points to be taught in this section are introduced; at the end of the video, the knowledge points in this section are reviewed systematically so that teacher learners can have a complete idea of what they have learned[17].

In the post-processing of MOOC video, the grasp of the video rhythm should be paid attention to, and the key knowledge and content of this section should be high-lightened. Moreover, in order to adapt to the shooting lens, teacher trainers should conduct speech exercises in advance and exercise their own language expression ability so that in the formal MOOC video recording, they may achieve natural tone and facial expression, use reasonable language and express clearly.

\section{Application of MOOC in flipping classroom in teacher's continuing education}

In the continuing education of teachers, the application of MOOC in the flipping classroom is mainly divided into three parts, namely the application of MOOC in pre-class knowledge dissemination, the application of $\mathrm{MOOC}$ in classroom knowledge internalization and the application in after-class reflection.

Based on MOOC's knowledge dissemination before class From the perspective of teachers, the application of MOOC in flipping classrooms in teacher's continuing education fall into two kinds: the first one is that teachers are only users of MOOC videos, not producers; the second is that teachers are both producers and users. For the first type of teachers, they actually borrowed MOOC videos made by other teachers to teach. This requires teachers to select the appropriate MOOC video for the actual teaching, and internalize it into their own knowledge system through careful study, so as to guide the learners to pre-learning before the classroom teaching. For the second type of teachers, they can take the advantage of the powerful functions of the MOOC platform to observe and monitor at any time the learning progress of the teacher learners who are involved in education. In order to provide timely feedback to learners, teachers should also set up periodic assessments. Through this assessment, teacher trainers can also understand the effectiveness of their instructional design, and help them design scientific and effective teaching content and teaching methods. In addition, teacher learners can communicate and discuss with teachers and other teacher learners by the community in the MOOC platform while the teachers can learn the problems of the teacher learners in this way, which is convenient for teachers to provide targeted explanations in the discussion area.

Knowledge internalization based on MOOC in class The pre-class knowledge dissemination based on MOOC and the interaction between teachers and students lay the foundation for classroom teaching and also promote the internalization of teacher learners' knowledge. Because teacher learners participate in classroom teaching for a short time, the most important feature of the MOOC-based teacher's continuing education is to make full use of classroom time to organize the most effective classroom teaching. "Teacher learners can achieve the most effective learning though classroom teaching and their knowledge internalization achieves maximum effect. [18]"

Firstly, teacher trainers summarize and analyze the learning progress of teacher learners based on MOOC video learning before class, and sort out the problems or difficulties the learners raised during the learning process. Then these problems and difficulties will be used to determine the topics of class discussion, and then these topics are conveyed to learners through the MOOC platform for them to make preparation to discuss and give explanation in the class.

Secondly, when discussing the topics, teacher learners will conduct group discussion in the form of collaborative learning, and select the group representatives to share the discussion results of each group to the whole class. Then the teacher trainers and each group will give comments. In this process, teacher trainers, as the instructors and helpers of the teacher learners, should allow teacher learners to fully participate in the context of collaborative learning and encourage them to conduct independent research. From the perspective of teacher 
learners, they learn in advance according to the MOOC video materials provided by the teacher trainers, and they can quickly engage in the learning session in the classroom. In the classroom teaching process, teacher learners raise questions by watching the MOOC video, they interact with teacher trainers and their peers in group discussion and they evaluate the discussion results. This series of classroom teaching links not only promote the internalization knowledge of teacher learners, but also enhance their motivation to learn.

Rethinking based on MOOC after class AS for teacher trainers, they should reflect on the learning situation of learners watching MOOC videos and the participation in teaching activities and then adjust and optimize teaching plans and teaching methods accordingly, thereby promoting teacher learners to better absorb knowledge. AS for teacher learners, they should reflect on their learning of MOOC videos before class and the resolution of problems in class, thus promoting their better understanding and internalization of what they have learned.

\section{Conclusion}

In summary, the society has great demand for teachers' continuing education, and the arrival of the MOOC era has brought tremendous development opportunities for teachers' continuing education. The application of MOOC in teacher continuing education not only enables teacher learners to achieve fragmented learning anytime and anywhere, but also meets the individual needs of teacher learners.

\section{Acknowledgement}

Found program: The thesis is a phased achievement of the funding project : Shaanxi Provincial On-line Open Course Construction of Teacher Education: English Writing (Program No.: JSMK1723)

\section{References}

[1] The 13th Five-Year Plan for Economic and Social Development of the People's Republic of China (the 13th Five-Year Plan ) [N] Xinhua Net, March 17, 2016 21:52.

[2] He Shurong \& Zhang Yinghua, Opportunities and Challenges Faced by Farmer Education in the Age of MOOC [J] Journal of China Adult Education, 2015(4):20

[3] $\mathrm{Lu} \mathrm{Bo}$, Investigation and Analysis of the Status Quo of Continuing Education of Rural Primary and Secondary School Teachers [J] Journal of China Adult Education, 2007(9).

[4] Lian WEifeng. Reflections on the Problems Existing in the Continuing Education of Primary and Secondary School Teachers [J] . Journal of Continuing Education Research, 2010(5).

[5] Guo Ling An Analysis of the Continuing Education of Rural Primary and Secondary School Teachers [J]. Journal of Adult Education College of Hubei University, 2007(2).

[6] Shi Yuxin Investigation and Thoughts on the Status Quo of Continuing Education of Rural Primary and Secondary School Teachers in Hebei Province [J]. Journal of Hebei Normal University ( Education Science Edition), 2008(8).

[7]Li Ping Problems and Countermeasures in the Continuing Education of Primary and Secondary School Teachers [J]. Journal of China Adult Education, 2008(7).

[8] Zhu Xiaodong, Guo Feixiang Problems and Countermeasures of Continuing Education for Rural Middle School Teachers [J]. Journal of Continuing Education Research, 2008 (10).

[9] Huang Yu, Cao Wangjin. Three Models of Continuing Education for Primary and Secondary School Teachers [J]. Journal of Anqing Teachers College (Social Science Edition), 2002(4) .

[10] Wu Jianping. University Revolution - Higher Education in the MOOC Era [M]. Beijing: Tsinghua University Press, 2014: 92.

[11] Tian Baojun, Jiang Mengmeng. Limitations and Overcoming Strategies of MOOC in Adult Education[J].Journal of Hebei Normal University(Educational Science Edition),2016(3).

[12] Knowles, M. S.. Andragogy, not pedagogy. Adult Leadership, (1968) 16(10), 350-352, 386.

[13] Chen Li Foundation of Distance Education [M] Beijing: Higher Education Press, 2004:71.

[14]. Shang Feifei\&Fu Jingchuan. MOOC and the Transformation of Adult Education in China [J] Journal of China Adult Education, 2015(11).

[15]. Ding Wanyi\&Zhang Manjing. The Transformation of Teachers' Function in Adult Higher Education under the Trend of MOOC [J]. Journal of Adult Education, 2016(5).

[16] Li Qi. MOOC Raising Ethical Issues in Adult Education [J]. Journal of Chinese Social Sciences, 2015(10).

[17]Yuanna XU The Mode Reform of Superior Education in the MOOC Times, [J] Journal of Higher Education of Social Science, 2015 (3).

[18]Hou Longzhen. Analysis of the Applicability of MOOC in Adult Learning [J]. Journal of Vocational Education News, 2015(1). 